which induces the sufferer to scrutch off the covering cuticle, causing the erythematous effinsion to develop a blood-scab. Its characteristics are shown on the backs of the hands and about the ankles, and may be mistaken for mosquito bites. 3. A copper-coloured papule of largish dimensions, on whose surface after twelve hours may or may not appear a pustule. The front of the thorax exhibits this best. The older pathology which regarded prickly heat (lichen tropicus) as a papular eruption, and the more recent, as vesicular-hence termed "miliaria papulosa" - are both partially correct, but also erroneous, inasmuch as they recognise a single lesion. The treatment of all consists in washing the affected parts freqnently with superfatted menthol, eucalyptol, or phenol (20 per cent.) soap, allowing the rabbed-in foam to dry, then mopping on with a sofb linen rag this lotion: liquor plumbi subacetatis, liquor carbonis detergens, and glycerine, of each one ounce; rectified spirit of wine, three drachms; oxide of zinc, two drachms, to a pint of water; or smearing with the following ointment : vaseline, two drachms; ldnoline, two ounces ; liquor earbonis detergens, two drachms; oxide of zlnc, one drachm ; menthol, twenty grains. If of limited extent, a bismuth and zinc powder may replace these. Cotton underclothing should be adopted and frequently changed.

Bunbury, Western Australia.

\section{FORCEPS AS AN AID TO VERSION.}

By W. HeNry Harris, L.R.C.P.ED. \& s.

A CASE I was called to at a long distance by two medical men in attendance in Manitoba may not be without interest. On arrival, I found the patient, aged twenty, in labour, then some twenty hours; primipara; seven monthe. On examination I found the right arm protruding (had been so some hours, the patient having been kept under chloroform), the right shoulder firmly jammed, and constant powerful aterine contractions, so that the introduction of the hand for version seemed impossible. It occurred to me that if I could apply the forceps (Simpson's long) on the thorax at a point a little belowits greatest diameter, gentle pressure would cause the blades to descend towards the pelvis, and so convert the presentation into an ordinary breech. The result was as I anticipated. In this case the foetus had been dead some hours and the labour premature. My reason for publishing this case in THE LANCET is that I do not see "forceps as a means of version" quoted in the texb-books, as well as to suggest that similar means might be applicable in cases where such an unfortunate presentation has occurred.

Maidstone.

\section{9. dutirur}

\section{H OSPITAL PRACTICE, BRITISH AND FOREIGN.}

Nulla autem est alia pro certo noscendi via, nisi quamplurimas et mcr forum et dissectionum historias, tum aliorum tum proprias collectas abere, et inter se comparare-MorgagNI Do sed. et Cars. Morb. lib. iv. Procemium.

\section{GUY'S HOSPITAL.}

FRACTURE AND DISLOCATION OF THE PELVIS; INTRAPERITONEAL RUPTURE OF THE BLADDER;

PNEUMONIA ; DEATH.

(Under the care of Mr. W. ARButhot LANE.)

THE amount of force required to produce a fracture of the pelvis to the extent described in this case is very considerable. We may remind our readers of the experiments to determine this question recently made by Dr. Areilza which we published in THE LANCET of April 2nd. Intra-peritoneal rupture of the bladder is not by any means a common complication in these fractures, injuries of other parts of the urinary tract much more frequently requiring surgical interference for their relief. It is difficult to say how long after it has occu red a rent in the bladder wall may be successfully sutured. Clinical rec rds prove that the peritoneum is much more tolerant of healthy urine than was at one time supposed; and in the cases treated by Drs. Schramm and Knight, as much as fifty and fifty-four hours had elapsed before an operation was performed, after which recovery ensued. This case is an interesting and important one.

A. F_, aged thirty-seven, a coalheaver, was admitted into Gay's Hoapital shortly after 4 P.M. in the afternoon of Feb. 23 $d$, 1892. He had been driving a heavy cart containing two tons of coals, when he fell off his seat, the front wheel of the cart passing slowly over his pelvis. When seen by Mr. Lave ab 5 P.M. he was extremely collapsed. There was a broad, bruised line running obliquely across the symphysis, indicating the course taken by the wheel. The several portions of the pelvis moved freely upon one another. There was no tenderness or rigidity of the abdomen, and be bore manipulation of it without complaint. At that time his condition was not such as to encourage operation, even had there been any indication to do it. He was therefore surrounded with hot bottles and made as warm as possible. He gradually improved, and in about two or three hours after the injury began to complain of a desire to pass urine, and developed tenderness and rigidity of the abdominal wall immediately above the symphysis. On passing a catheter a little bloody urine was drawn off. By 9 P.M. the patient had recovered sufficiently to bear an operation, so Mr. Lane opened the abdomen in the middle line about the symphysis, and found some bloody urine in the peritoneal cavity. There was a large transverse rent which admitted three fingers in the upper surface of the bladder, about an inch and a half from its anmmit, the adjacent portion of the bladder being much bruised and swollen. The innominate bones were found sepa ated at each synchondrosis and also at the symphysis, the fragments forming the last articulation being separated antero-posteriorly by an interval of an inch. It was apparent that the bladder had been jammed and divided by the forcible approximation of the pubic bone against the very prominent lower margin of the fifth lumbar vertebra, which, as in the case of all powerful coalheavers, was in a position of partial spondylolisthesis. The two pubic bones were placed in apposition, the rent in the bladder was closed by a continuous suture, the pelvis was sponged free of any blood and urine, and a glass tube was left in Douglas's pouch. No attempt was made to wash out the peritoneal cavity, as the urine and mucous membrane of the bladder appeared to be perfectly healthy. Subsequent to the operation bu 6 a very small quantiby of bloody fluid was sucked up out of the Keith's tube, which was removed shortly. Being only too well aware how of ten the subjects of such severe injuries die from pneumonia, every precaution was taken to keep him in a warm, moist atmosphere; bat in spite of every endeavour he developed a pleuritic rub on the left side on the day following the injury, and although his temperature on only one occasion rose to $101^{\circ}$, his respiration and pulse became progressively rapid, and he died on the evening of the $27 \mathrm{~b}$, four whole days after the injury. All abdominal pain, rigidity, and tenderness ceased, and all his urine was siphoned off through a rubber catheter tied into the bladder. At the post.mortem examination, both lungs were found in a condition of grey hepatisation, the disease being more advanced on the left side. The wound in the bladder had bealed perfectly, and there was no evidence of any peritonitis.

Remarks by Mr. LANE.-Though these cases of successful suture of rupture of the portion of the bladder wall covered by peritoneum are by no means very rare, yet I think that this case, though it terminated fatally, is worth publishing. The mode of production of rupture is certainly very unusual. It serves to illustrate the fact that the peritoneal cavity is comparatively tolerant of healthy urine, and affords another example of the frequency with which a patient, the subject of a severe injury, may die of pneumonia often unaccompanied by any particular rise of temperature, although the chest itself has sustained no injury, and every precaution has been taken to shield the patient from chill. Except for the unfortunate onseb of the pneumonia he might have recovered. 